\title{
NAVEGAR É PRECISO, VIVER NÃO É PRECISO': PROJETO E PESQUISA ACADÊMICA
}

\section{PERRONE, RAFAEL ANTONIO CUNHA}

Professor Livre Docente da Faculdade de Arquitetura e Urbanismo da Universidade de São Paulo, Prof. Dr. Adjunto da Faculdade de Arquitetura e Urbanismo da Universidade Presbiteriana Mackenzie. Email: arqperrone@gmail.com

\section{RESUMO}

O artigo discute a situação das disciplinas de Projeto de arquitetura nos cursos de pós-graduação e sua inserção como atividade acadêmica. A partir das peculiaridades dos conhecimentos produzidos pela atividade projetual, propõe sua inserção na pesquisa acadêmica. Tendo como base 0 aspecto multidisciplinar que caracteriza a atividade da arquitetura, reconhece sua abordagem por meio de métodos de investigação de diversas áreas do conhecimento, como uma contribuição para uma "arquitetologia". Desloca a classificação da área projetual de uma equivocada classificação como uma mera prática, situando-a como um reflexionamento propositivo. Defende a possibilidade de reconstituição do Projeto como atividade de investigação acadêmica e como produtor de conhecimentos.

PALAVRAS-CHAVE: projeto de arquitetura; pesquisa acadêmica; pesquisa em área de práticas projetuais; teoria e prática da arquitetura; escrita acadêmica.

\section{RESUMEN}

El artículo discute la situación de las disciplinas de proyecto de arquitectura en los cursos de posgrado y su inserción como actividad académica A partir del peculiar tipo de conocimiento producido por la actividad proyectual, posiciona su inserción en la investigación académica. Dentro del aspecto multidisciplinar que caracteriza la actividad de la arquitectura, reconoce su abordaje por investigaciones y métodos de diversas áreas del conocimiento, como contribución para una "arquitetologia". Retira la clasificación del área proyectual de una equivocada clasificación como una mera práctica, situándola como un reflexionamento propositivo Defiende la posibilidad de la institución de Proyecto como actividad de investigación académica y como productora de conocimientos.

PALABRAS CLAVE: proyecto de arquitectura; investigación académica; investigación en área de práctica proyectual; teoría y práctica de la arquitectura; escritura académica.

\section{ABSTRACT}

The article discusses the situation of the Design discipline dealt within the courses of postgraduate studies and its insertion as an academic activity. Beginning with the peculiar type of knowledge produced by the design activity, the former mentioned article inserts itself in academic research areas. Inside the multidisciplinary aspect that characterizes the architecture, it recognizes its approach through research and methods of diversified areas of the knowledge, as a contribution to architecture itself that would be called "architectologie". The article removes the classification of the design's area from an erroneous position such as practice, situating it as a propositional thinking. The paper argues in favor of recognizing Design as an academic research and a knowledge producer.

KEYWORDS: architectural projects; academic research; design disciplines; theory and practice of architecture; academic writing.

Recebido em: 11/08/2020

Aceito em: $24 / 11 / 2020$

\section{INTRODUÇÃO}

\section{Arquitetura e saberes}

As disciplinas projetuais operam com a previsão do futuro, instituem por seus conhecimentos as possibilidades de previsibilidade da vida, sua precisão trabalha para aperfeiçoar propostas para aprimorar o existente e reduzir o imprevisível, operando com um lançar à frente. Se os atributos da ciência navegam no aprimoramento da interpretação do conhecido, aperfeiçoando a precisão de seu entendimento, os atributos da arquitetura devem se constituir por saberes que permitirão a condução por "mares nunca dantes navegados"3. Viver só poderá ser preciso se formos capazes de projetar a vida humana e do meio em que ela se desenvolverá, contando com certa e calculável imprevisibilidade de nosso futuro. 
Esta constatação de ordem ontológica sobre o significado do projeto de arquitetura e de seus saberes, seus ensinamentos e suas pesquisas, o situam numa área de difícil tratamento e classificação dentro do mundo acadêmico.

Neste entendimento ontológico, há uma inquietação a respeito do que é a produção de conhecimento na área de arquitetura. A pergunta que se insinua, na esfera acadêmica das universidades brasileiras, a partir da inserção nelas das disciplinas projetuais é: em que se constituem os saberes da arquitetura, como são produzidos? Em outras palavras, o que consiste, nos trabalhos acadêmicos, aquilo que se pode considerar uma investigação científica de arquitetura? O que pode ser considerado como produção de conhecimento na arquitetura?

Se nos cursos de graduação, no Brasil, as disciplinas de projeto se situam no centro das preocupações do ensino, nos cursos de pós-graduação, ao contrário encontram-se, no mínimo, numa situação desconfortável como já se notou quando da instalação e desenvolvimento de vários cursos de pós-graduação no campo da arquitetura (MAHFUZ, 2002; VELOSO e ELALI, 2002; PERRONE, 2001). Observa-se, também, a continuidade desta preocupação em estudos mais recentes como os registrados por Del Castillos (2017) em sua tese:

\begin{abstract}
O Projeto, apesar de constituir o núcleo epistêmico da arquitetura e do design e de ocupar um papel central nos planos de ensino na formação do arquiteto, ficou tradicionalmente confinado ao âmbito da prática, com escassa participação do mundo da pesquisa. A pesquisa desenvolvida nos doutorados de arquitetura, inclusive aquela que se inscreve nas áreas de projeto, aborda principalmente o estudo de obras construídas e projetos realizados, articulando métodos da historiografia com técnicas e recursos próprios da área do projeto. Raramente explora o potencial do projeto para pesquisar sobre o futuro. (DEL CASTILLOS, 2017, p. 29).
\end{abstract}

Poderíamos dizer, a partir de Zevi (1986), que a arquitetura se constitui por suas obras e pelo legado real de sua experimentação. Assim, "todas as obras que não ofereçam uma experiência real da cavidade espacial e dos volumes - incluindo os projetos e as reconstruções ideais dos documentos - são fantasias, suposições e não expressões arquitetônicas" (ZEVI, 1986, p. 128).

Arquitetura é, portanto, por ele entendida como o arsenal disponível constituído pela presença de suas obras edificadas, nas quais se pode vivenciar o espaço nelas existente.

A partir disto, os novos conhecimentos da arquitetura se formariam por meio da edificação de novas obras que permitiriam a vivência ou experimentação, pois, nelas e só nelas, residiria a arquitetura.

A arquitetura, entretanto, não se resume às obras edificadas. Por ser uma disciplina que se encarrega de dar previsibilidade ao futuro, devendo transformar o imprevisível no deduzível, o esperável no proposto, o provável no calculável e o imaginado no construível, a arquitetura não se resume a uma prática de conceber ou erigir construções, mas um conjunto de saberes e reflexões que permite criá-las, dando-lhes a capacidade para abrigar desejos e necessidades.

Sua utilização como centro de uma dissertação de mestrado ou de uma tese de doutorado, como proposição teórica ou científica, tem sido contestada por parte da comunidade acadêmica.

Procura-se neste artigo, dentro desta visão de Arquitetura, debater estas questões e os formatos de sua inserção no campo acadêmico. Esta discussão entre Projeto e pesquisa, como é muito ampla, será situada nos seguintes itens: Vertentes de entendimentos dos saberes; Arquitetura e ciência; Arquitetura, teoria e prática projetual; argumento textual e argumento gráfico.

\title{
2 DESENVOLVIMENTO
}

\section{Vertentes dos saberes}

Estes saberes e reflexões se fundam em três grandes vertentes: nas tecnologias que permitem a construção dos artefatos, nas ciências humanas que permitem o entendimento das relações entre os homens e nas artes pelas quais se exprimem e comunicam valores.

Nestas três vertentes a arquitetura acaba por recolher conhecimentos que possuem métodos e abordagens, em parte, bastante distintos. Nas ciências tecnológicas por procedimentos quantitativos, processos dedutivos, métodos empíricos, relativamente estabelecidos. Nas ciências humanas por meio de análises sociológicas e historiográficas, métodos empíricos, amostragens, cujos corpos de regras e diligências, também contém certa solidez. Na área das artes, entretanto, pelo seu caráter distintivo das ciências, as dificuldades de abordagem acadêmica se tornam maiores (BIGGS E BÜCHLER, 2008). 
É provável que por este motivo se observe, nos trabalhos acadêmicos realizados no Brasil, uma grande produção relativa às duas primeiras áreas e muitas inquietações quando se trata das disciplinas projetuais. Para a academia, haveria um arquiteto e um "arquitetólogo", ou seja, um conhecimento competente para fazer arquitetura e um conhecimento para estudar ou para saber sobre arquitetura.

Neste caso, há duas noções que devem ser discutidas. A primeira é que situa o conhecimento do arquiteto como uma prática profissional. A segunda é a de que se confunde a figura do arquiteto com a do arquitetólogo.

Reduzir a atividade do arquiteto a uma prática conduz a uma série de equívocos, pois por extensão, poderia ser tratada a pesquisa da história, como a prática do historiador; a produção do pensamento, como a prática filosófica; a da ciência como a da prática científica. Nenhuma destas atividades pode ser tratada como prática, melhor seria se a atividade de Projeto de arquitetura, em muitos casos pudesse ser entendida, como outras ações humanas, como investigações e referências que conduzem a um reflexionamento propositivo.

Neste caso a noção de profissão deve deixar de ser, apenas, a de uma ocupação ou ofício e retomar o sentido em que está imbricada: a de ser um conhecimento professo. Registre-se que profissão e professor, derivam de mesma raiz etimológica, - do latim professor,oris e profissio , onis, do rad. de professum; confessar, mostrar, dar a conhecer; divulgar, publicar; fazer profissão de, exercer um mister; professar, ensinar, ser professor, mestre (HOUAISS, 2001, p. 2.307-2.308).

No entendimento da diferenciação entre o arquiteto e o estudioso da arquitetura deve haver uma distinção em dois grupos: no primeiro encontram-se os arquitetos que por formação também são arquitetólogos, no segundo grupo os arquitetólogos são profissionais ou acadêmicos de outras áreas de conhecimento.

No primeiro grupo, a investigação acadêmica pode ser verificada em trabalhos significativos, entendidos como pertinentes ao campo da teoria, escritos e, por vezes, desenhados por exímios praticantes como Serlio, Alberti ou Palladio, no passado, ou como Le Corbusier, Rossi, Venturi ou Koolhaas em épocas mais recentes.

No segundo grupo que investiga a arquitetura a partir de outras áreas, encontram-se, por exemplo, Donald Schon, que no livro The Reflective Practitioner (1993) reviu a forma com que se compreendia a formação dos profissionais reconhecendo o papel do conhecimento técnico versus o conhecimento acadêmico no desenvolvimento da excelência profissional. Alain de Botton é também filósofo e dedicou parte de seu trabalho a vários temas contemporâneos, enfatizando a relevância da filosofia para a vida cotidiana. No seu livro The Architecture of Happiness (2008), discutiu a natureza da beleza na arquitetura e como ela está relacionada ao bem-estar e ao contentamento geral do indivíduo e da sociedade. E Edward Robbins, antropólogo que investigou em seu livro Why the architects draw (1994), as razões pelas quais os arquitetos trabalham por meio de desenhos.

A contribuição de conhecimentos acerca da arquitetura, portanto, pode advir de muitas áreas que a contemplam sob a ótica dos métodos e formas de expressão de cada uma delas.

No grupo de arquitetos-arquitetólogos, alguns acadêmicos, como Abrahão Sanovicz (1933 - 1999), ligado às disciplinas projetuais, tem buscado defender as atividades de projeto como atividades de pesquisa, buscando definir algumas peculiaridades e especificidades da ação projetiva nas dissertações e teses da área (SANOVICZ, 1990).

Dentro desta vertente, alguns arquitetos pretendem que seus projetos sejam apresentados como produtos de pesquisa acadêmica, mas isto, na opinião geral como de Serra (2006), pode ser contestado, pois embora o fato de que "ninguém nega que para elaborar um projeto é suposto que o arquiteto ou engenheiro realize alguma pesquisa; entretanto, em poucos casos esta pesquisa pode ser chamada de científica" (SERRA, 2006, p. 16).

No segundo grupo, muitos acadêmicos têm de um modo geral, se inclinado a compreender como trabalhos de pesquisa, aqueles que, diferindo das práticas ditas profissionais, possuem um método ou uma sistematização capazes de estabelecer reflexões ou conclusões acerca do campo de estudo dos edifícios e das cidades.

Estas considerações são afirmadas pelo texto de TILL "Is doing architecture doing research?" (2011) o qual, após ter discutido as noções de que a disciplina da arquitetura não é isolada de outros campos de pesquisa acadêmica e fundada em mitos de genialidade e autonomia, declara:

Projetar um edifício não é necessariamente uma pesquisa. O edifício como um edifício reduz a arquitetura para silenciar objetos. Eles mesmos não são suficientes como material de pesquisa. A fim de mover as coisas, para adicionar ao armazenamento de conhecimento, precisamos entender o processo que levou ao objeto e interrogar a vida do objeto após a sua conclusão. (TILL, 2011, p. 60) (tradução do autor). 
O fato é que dentre as polaridades destes grupos persistem as dualidades entre arte e técnica, teoria e prática. Mesmo que se pudesse transferir de todas outras disciplinas, abarcadas pela atividade projetual, o conjunto de contribuições de seus métodos, não se resolveriam, plenamente, pela peculiaridade da arquitetura, as questões acerca de uma identidade disciplinar.

Os conhecimentos produzidos pela arquitetura emergem da fusão de pluralidades próprias dos saberes e produtos arquitetônicos. Teoria e prática formam o contraponto da arquitetura. Ratio-cinatio e Fabrica, ou ars e scientia, ou mesmo design e construção, é sempre essa bipolaridade que a arquitetura pode ser compreendida, que a história da arquitetura pode ser contada (PLACZECK,1993, p. 9).

Esta fusão se deve ao fato de que a arquitetura, embora constituída por saberes tidos como práticos ou teóricos, não se identifica, nem os isola em áreas distintas, pois desenvolve, com técnica e arte, capacitações para imaginar e construir artefatos novos adequados a necessidades atuais ou futuras, além de consolidar e examinar procedimentos e artefatos já elaborados. Na primeira manifestação conhecida como um tratado da arquitetura, Vitrúvio já delineia:

A ciência do arquiteto é ornada de muitas disciplinas e de vários saberes, estando a sua dinâmica presente em todas as obras oriundas das restantes artes. Nasce da prática e da sua teoria. A prática consiste na preparação contínua e exercitada da experiência, a qual se consegue manualmente a partir da matéria, qualquer que seja a obra de estilo que cuja execução se pretende. Por sua vez, a teoria é aquilo que pode demonstrar e explicar as coisas trabalhadas perante o engenho e à racionalidade. Por isso. Os arquitetos que exerceram sem uma formação teórica, mas apenas com base na experiência de suas mãos não puderam realizar-se ao ponto de lhes reconhecerem autoridade pelos seus trabalhos.; também aqueles que se basearam somente em teorias e nas letras foram considerados como perseguindo uma sombra e não a realidade. Todavia, os que se aplicaram numa e noutra coisa, como que protegidos por todas as armas, atingiram mais depressa, com prestígio, aquilo que se propuseram (VITRÚVIO, 2006, p. 30).

\section{Arquitetura e ciências}

Volte-se à questão do conhecimento científico.

Nas ciências, uma teoria adquire seu estatuto se suas hipóteses de explicação, para um determinado fenômeno ou uma determinada conexão, forem verificadas após terem sido submetidas a controles do raciocínio ou da crítica experimental. Uma teoria define-se, em linhas gerais, por meio de uma concepção metódica, sistemática e organizada, construída por um formato e por certas decisões ou convenções científicas que não pertencem ao senso comum.

Nesse sentido, ao se propor o conhecimento ou explicação, a teoria tem como finalidade, dentro de certos parâmetros, interpretar - "como as coisas são". Sua extensão lógica é a de que explicando um fenômeno, seja capaz de estabelecer previsões, por intermédio de conexões dedutíveis a partir de sua formulação. Sua permanência vincula-se a seu constante cotejamento com o objeto que explicou, sendo submetida à verificação crítica dos fatos novos que possam aparecer sob seu domínio. No conhecimento científico, estas conexões lógicas entre as "coisas" e suas explicações estão compreendidas, grosso modo, dentro de um quadro referencial, em dois grandes grupos: as ciências formais e as ciências empíricas (OLIVA, 2003).

As matemáticas e a lógica, por não tratarem com objetos empíricos, enquadram-se na primeira categoria, constituem seus conhecimentos, por meio de procedimentos de natureza dedutiva. As suas proposições não estão vinculadas à explicação dos fatos, mas decorrem de uma cadeia de raciocínios derivados de sua própria natureza e consistência.

As outras ciências tidas como empíricas estão agrupadas em duas categorias: as ciências da natureza e as ciências sociais. Nelas, a construção de conhecimentos e teorias decorre da observação de fenômenos de forma direta ou indireta. Para estabelecer relações e conexões, gerando teorias interpretativas entre estas observações, são utilizados instrumentos de abordagem e métodos quantitativos e qualitativos. As explicações necessitam cotejar os dados observados (ingredientes empíricos) com formulações interpretativas (ingredientes teóricos). O conhecimento será produzido por um conjunto de técnicas inferenciais, predominantemente de base indutiva.

Entretanto, mesmo no caso destas ciências devem ser utilizadas relações entre as lógicas formais e as empíricas, de modo que a conjugação entre observações e formulações só pode ser estabelecida ao validar se determinada assertiva é ou não verdadeira, pelo fato de poder ser concluída a partir das supostas "certezas" das demais proposições utilizadas. O raciocínio indutivo utiliza-se do dedutivo e de suas lógicas 
para consolidar suas teorias. O desenvolvimento das teorias emerge, em suas raízes, do encontro de dois modos de entendimento da epistemologia: a apreensão e o entendimento de um fenômeno.

O método científico é entendido como a superação da visão mágica ou religiosa do mundo, insistindo numa busca sistemática de conhecimentos pela qual se pode compreender e dominar a realidade e erigir um mundo humanizado. Este é conseguido aliando a explicação dos fenômenos ao domínio da natureza, tanto quanto o entendimento das relações humanas necessárias ao funcionamento de sua vida cultural e social.

Mas as teorias têm sentido muito restrito se forem utilizadas somente para compreender determinados fenômenos ou se restringir a dizer como as "coisas são". Ao conhecimento compete em grande medida prognosticar eventos futuros ou ao menos possibilitar a compreensão de novos fatos que possam ter relações significativas com os fenômenos ou objetos de estudo pesquisados.

Em seu sintético livro sobre as ciências sociais, A Teoria Crítica, Marcos Nobre expõe os fundamentos da Escola de Frankfurt, mostrando-nos o sentido de uma análise de "como as coisas são" do ponto de vista de "como deveriam ser". A constituição de saberes, a partir de uma visão crítica da teoria, desperta-a de seu caráter paralisante, principalmente, quando utilizada para a análise de fenômenos sociais, cuja dinâmica de transformação é constante e mutável. Exige-se de uma teoria social muito mais que uma explicação, pois a continuada observação das configurações sociais e as possíveis alternativas interpretativas requerem uma teoria, em constante crítica de sua própria explicação.

\begin{abstract}
Note-se, ainda, que não se trata tampouco de abdicar, de conhecer, de dizer 'como as coisas são', nem de abdicar da tarefa teórica de produzir prognósticos. Ocorre que, do ponto de vista crítico, aquele que separa rigidamente 'como as coisas são' de 'como devem ser', só consegue dizer 'como elas são' parcialmente, porque não é capaz de ver que 'as coisas como devem ser' é também uma parte de 'como as coisas são'; porque não consegue enxergar na realidade presente, aqueles elementos que impedem a realização plena de todas as suas potencialidades. [...] Sendo assim, a teoria crítica não pode se confirmar senão na prática transformadora das relações sociais vigentes. As ações a serem empreendidas, para a superação dos obstáculos à emancipação, constituem-se em um momento da própria teoria. [...] A prática é um momento da teoria, e os resultados das ações empreendidas a partir de prognósticos teóricos tornam-se, por sua vez, um novo material a ser elaborado pela teoria, que é, assim, também um momento necessário da prática (NOBRE, 2004, p. 10-12),
\end{abstract}

As ciências humanas deveriam estar, de acordo com a teoria crítica, impregnadas de uma noção de projeto, pois o objeto de estudo deve ser analisado pelas potencialidades de seu devir. Deste ponto de vista, as próprias teorias das ciências humanas também, como as da arquitetura, não tratam, necessariamente, em campos distintos as áreas da teoria explicativa e da prática transformadora. Pelo contrário, a prática e a teoria são dois momentos conjugados nestas disciplinas.

\title{
Arquitetura, teoria e prática projetual
}

A arquitetura também pertence às ciências humanas e numa saudável relação com a Teoria Crítica pode estabelecer conhecimentos que nos fazem "explicar as coisas" pelo seu "ser" e possibilitar intervir em seu "devir".

Neste sentido, uma ação de pesquisa acadêmica pode ser vista como aquela que a identifica com o próprio projeto. O projeto se configura com a própria pesquisa, dando origem a expressões do tipo "projeto-pesquisa" ou "projeto-teórico".

Está claro que as considerações de que o projeto de arquitetura e/ou suas obras e processos, como manifestações de conhecimentos contêm sabedorias explícitas ou veladas. As obras são reconhecíveis diretamente como lições realizadas a partir da expressão dos reflexionamentos contidos e explicitados, ou seja, das propostas reconhecíveis que servirão como pontos de partida e referências para diversos projetos (PERRONE, 2011). Assim como interpretações de muitas delas devem ser reveladas por meio de pesquisas e transformadas em generalizações e teorias.

Desta forma, deve-se reconhecer que a produção de conhecimentos a partir da "reflexão-na-ação", propiciada pela atividade projetual está plena de saberes, porque toda obra projetual em "stricto sensu" (todo o projeto) é um laboratório de experiências conceituais, técnicas e formais. Além disso, sabe-se que o desenvolvimento de uma linguagem e de suas soluções depende do acúmulo de experiências que se constroem mediante uma sistematização a partir da produção. No Brasil, o caso do arquiteto João Filgueiras Lima (Lelé) é um caso exemplar com sua preocupação com a constituição de sistemas construtivos e racionalização da construção. Sua experiência seguida dos Hospitais da Rede Sarah Kubistchek permitiu que ele e sua equipe desenvolvessem um laboratório de aperfeiçoamentos que se constituíram, desde a reformulação do 
programa, geração de sistemas construtivos, novas hipóteses de arranjos, programas, móveis e até detalhes dos edifícios hospitalares;

Mas se a construção de saberes, por meio de projetos e obras, é um ponto pacífico no entendimento de todos os arquitetos, a adoção da atividade projetual enquanto construção de conhecimento, no ambiente acadêmico, ainda é um ponto polêmico.

Sua utilização como centro de uma dissertação de mestrado ou de uma tese de doutorado, como proposição teórica ou científica, tem sido contestada por parte da comunidade acadêmica.

Em um ensaio do arquiteto e educador John Hedjuk, Perez-Gomes defende a eficácia crítica do projeto não construído, da 'paper architecture' Daniel Libeskind e Zaha Hadid são outros arquitetos contemporâneos, cujos desenhos chamaram a atenção para seus autores (devido às novas características espaciais implícitas em seus projetos). "Exemplos mais antigos de projetos arquitetônicos de grande significação são a monumental 'arquitetura das sombras" de Etienne-Louis Boullée (Figura 1) e a série Cárceres de Piranesi, que confirmam a pujança da ideia desenhada. De maneira geral o papel do projeto teórico na disciplina, e inclusive a possibilidade de entendê-lo como parte da arquitetura propriamente dita, é controverso (NESBITT, 2006, p. 19).

Figura 1: Cenotáfio de Newton (1784). Arq. Etienne-Louis Boullé.

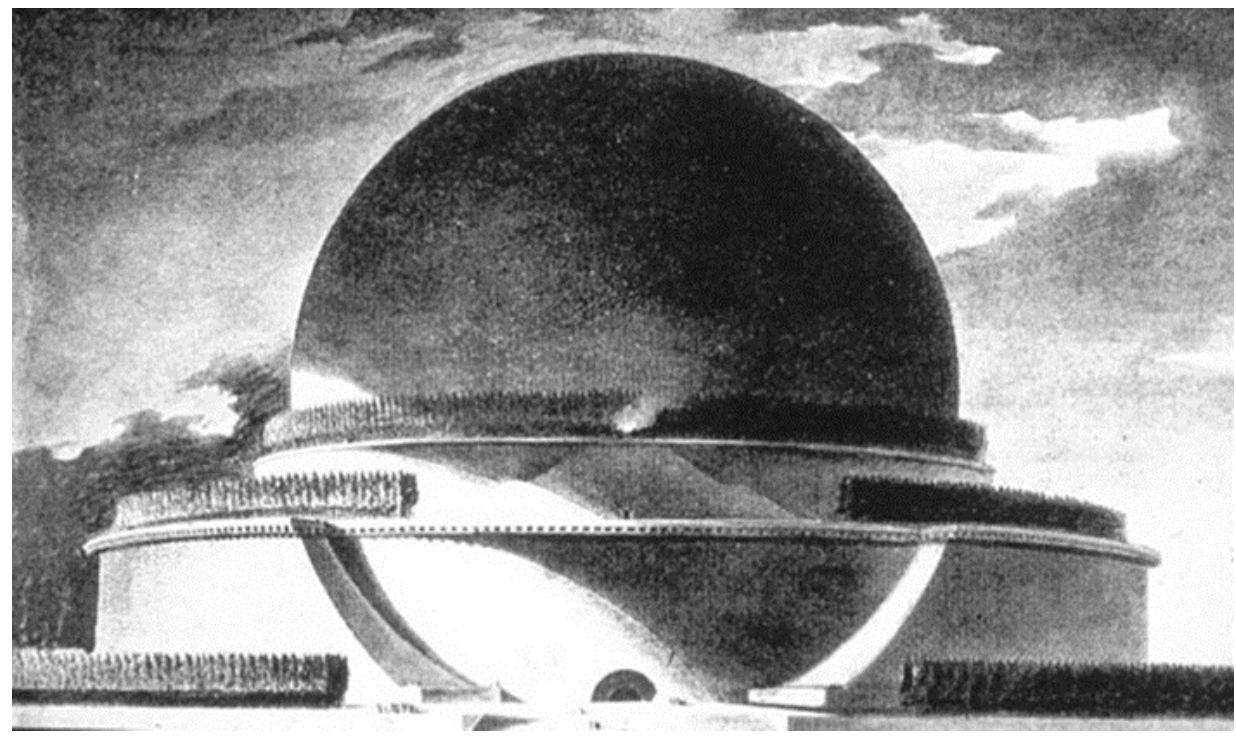

Fonte: Wikipedia < $<$ https://pt.wikipedia.org/wiki/Cenot\%C3\%A1fio de Newton>

Para muitos, essa aceitação de um projeto como argumento teórico é impossível, mas é bom registrar que grande número de projetos pode ser classificado nessa categoria, quer por suas constituições paradigmáticas quer porque o projeto "opera em diferentes níveis de abstração, avaliando a profissão de arquitetura, suas intenções e sua relevância cultural em geral" (NESBITT, 2006, p. 16). Constituem-se de registros gráficoteóricos que alavancam procedimentos, respondem a problemas existentes ou construídos, criticam conhecimentos estabelecidos e introduzem novas proposições.

Alguns destes projetos, embora ainda não tenham sido tratados dentro de um molde acadêmico, tem validade como paradigmas de ação projetual ou modelo referencial. Citem-se alguns deles, para este reflexionamento.

Enquanto desenho de cidades, por exemplo, a obra paradigmática de Tony Garnier - La Cité Industrielle (1901/1917) (Figura 2) registrou, idealizou e definiu uma série de proposições sobre a forma urbana abarcando as novas necessidades da urbe industrial. Sua importância é revelada por Wiebenson para a qual:

"[...] o estudo de la Cité Industrielle como expressão de seu ambiente e época só pode conduzir à conclusão de que a Citè é um dos mais completos planos ideais de qualquer período e que foi totalmente relacionada com a temática de seu tempo, provavelmente por isto, uma contribuição para a história da arquitetura e planejamento". (15) (WIEBENSON, 1969, p. 39) (tradução do autor). 
Figura 2: Cité industrielle (1901-1904). Arq. Tony Garnier.

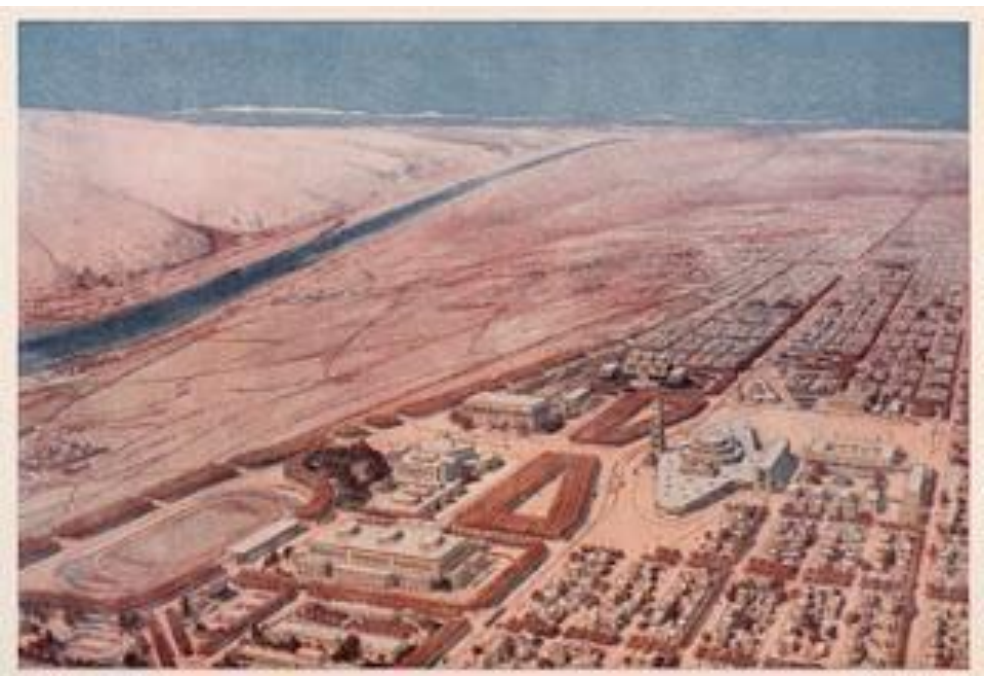

Fonte: Une citté Industrielle, Tony Garnier (1917). Acervo da Biblioteca da Escola Politécnica da Universidade de São Paulo.

Outro exemplo de projeto-pesquisa se caracterizou por uma reflexão acerca da racionalização da cozinha. Em 1927, a arquiteta Grete Schütte-Lihotzky, da equipe de Ernst May, realizou o projeto da Frankfurter Küche (Figura 3) na qual estudou as operações domésticas, buscando facilitar os afazeres do preparo e guarda de alimentos. A cozinha projetada foi instalada na maioria dos conjuntos edificados por aquela municipalidade. Além disso, é com sua aparição "que os equipamentos de cozinha transformados em produtos industriais farão sua entrada na habitação mínima da nova arquitetura" (KOOP, 1999, p. 46).

Figura 3: Cozinha de Frankfurt (1927). Arq. Grete Schütte-Lihotzky.

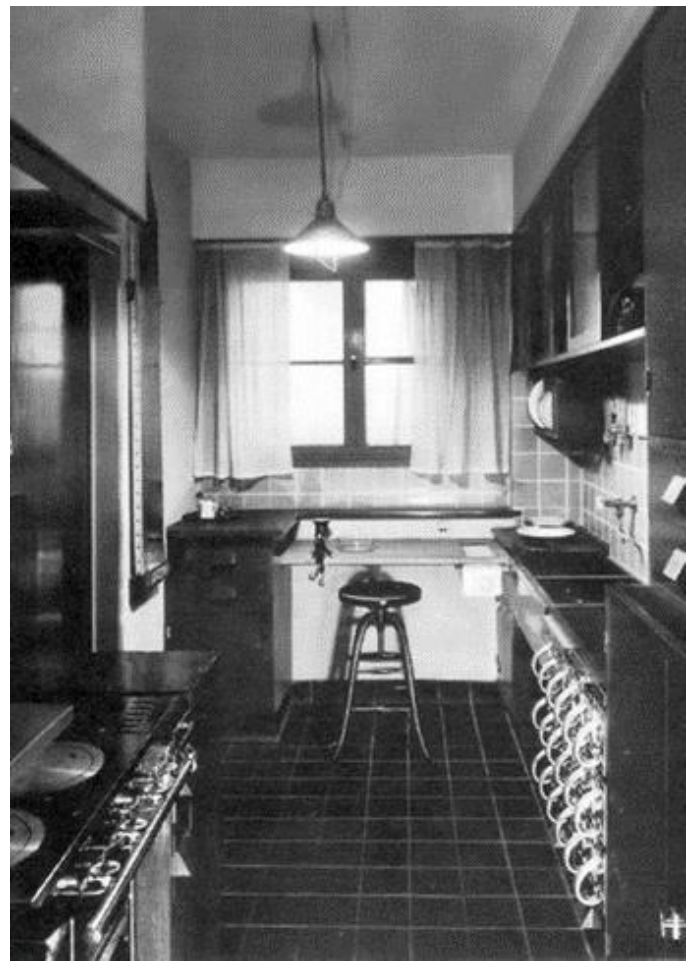

Fonte: Wikipedia <https://pt.wikipedia.org/wiki/Cozinha de Frankturt>.

Pode, também, ser lembrado, sem ao menos ter sido construído, o projeto das residências Dom-inó, de Le Corbusier (1915) (Figura 4), onde associou a ideia de domus (casa) com o jogo de dominó, indicando possibilidades de serem criadas variantes ricas, para o acoplamento de unidades produzidas por novas técnicas, atendendo por meio de uma estrutura de dois pavimentos as diversidades de programa interno de cada morador. 


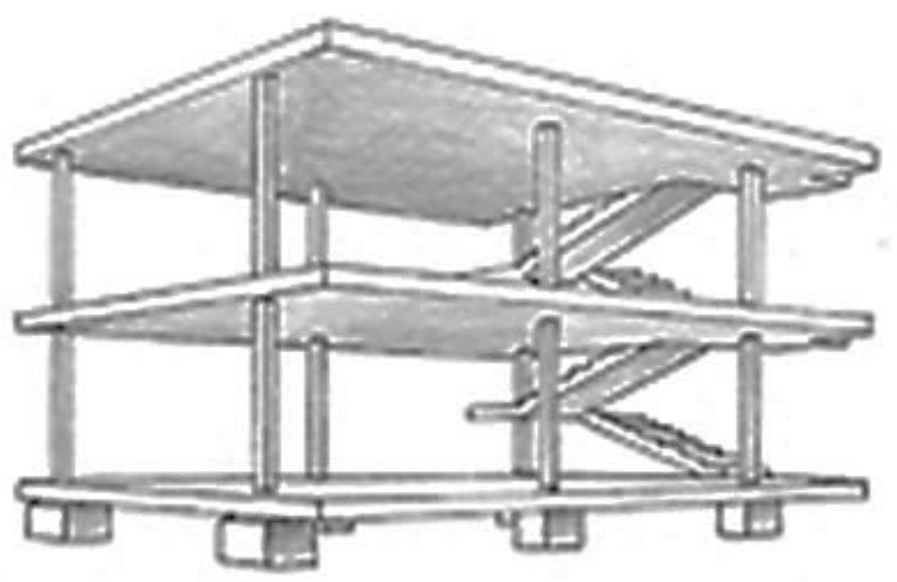

Fonte: Desenho do autor a partir de Le Corbusier.

Outro projeto pode ser associado a esta lista, trata-se de um conjunto de desenhos realizados pelo arquiteto Antonio Sant'Elia para o que imaginava ser a Città Nuova (1914) (Figura 5). Seus registros gráficos influíram significativamente nas propostas urbanas de Le Corbusier e, mais tarde, no desenho de Brasília, capital do Brasil.

Figura 5: Città Nuova (1914). Arq. Antonio Sant' Elia.

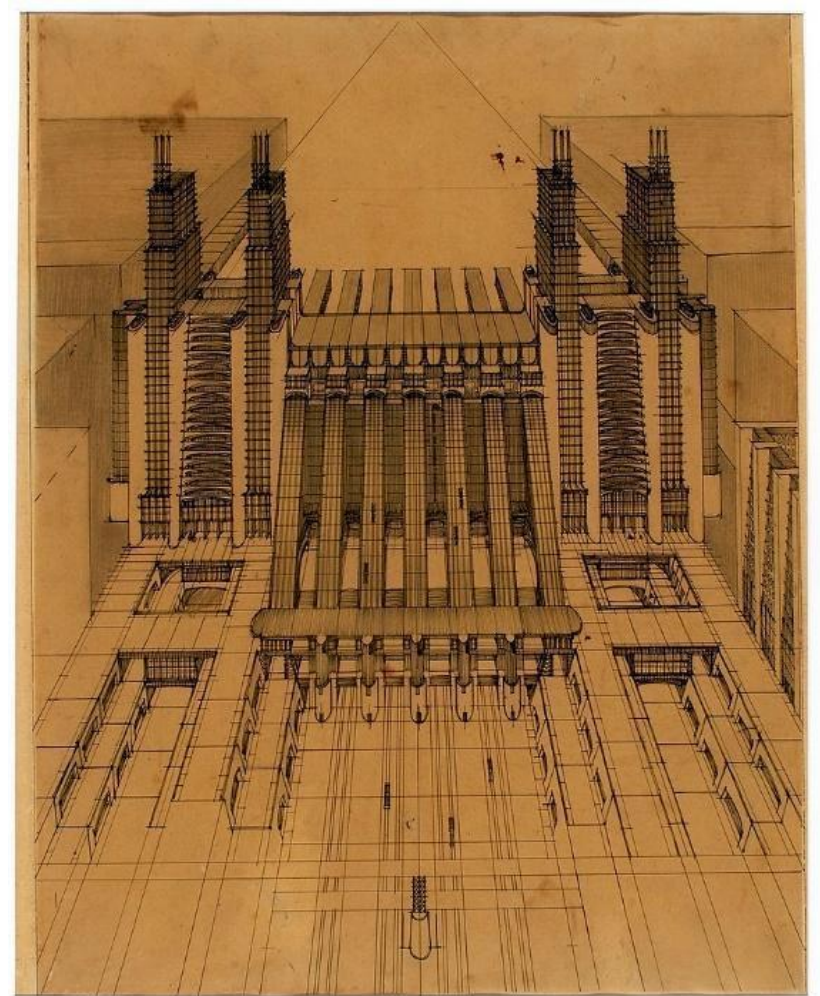

Fonte: <https://en.wikipedia.org/wiki/Futurist architecture\#/media/File:Stazione Sant'Elia.jpg>.

As obras ou projetos de arquitetura não são uma mera ilustração de argumentos teóricos, mas sua própria expressão, projetos como a Vanna Venturi House (1962) (Figura 6), de Robert Venturi, as casas de Peter Eisemnan (Figura 7) o Teatro del Mondo (1979) (Figura 8), de Aldo Rossi, são manifestações claras de seus propósitos atuando como signos não verbais, pelos quais a produção de conhecimento da arquitetura é afirmada, transmitida, compreendida e passível de ser transformada. 
Figura 6: Casa Vanna Venturi (1962). Arq. Robert Venturi.

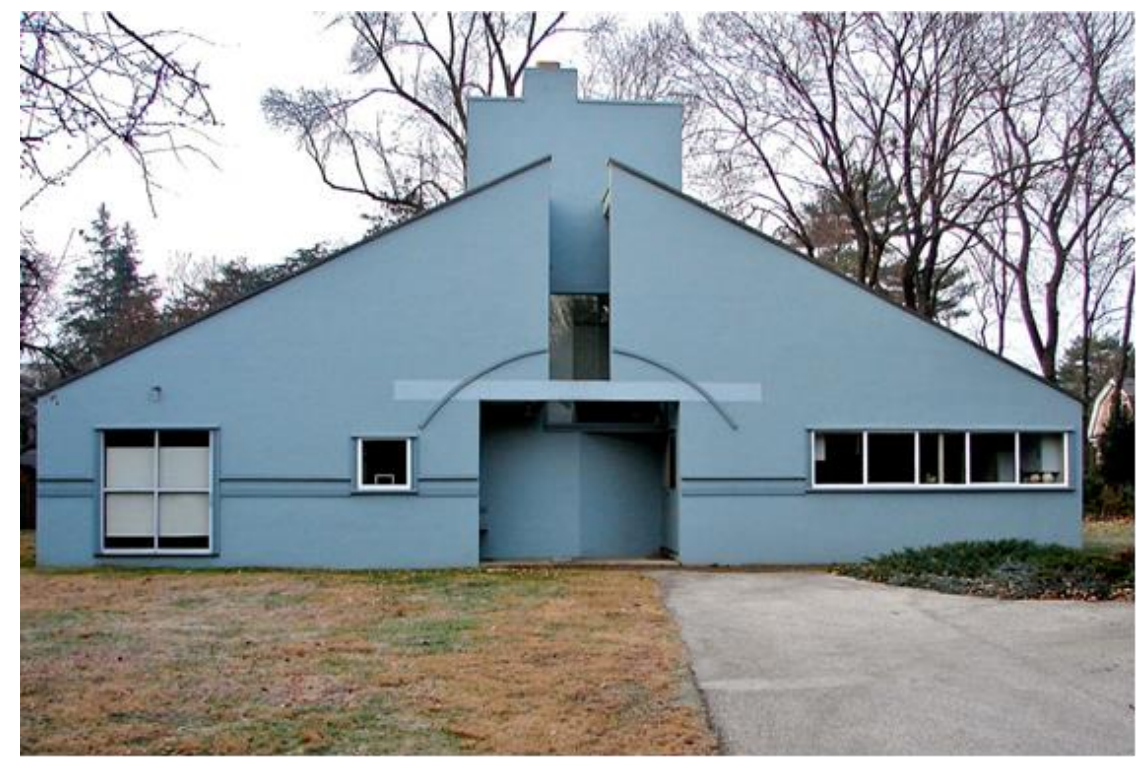

Fonte: <https://en.wikipedia.org/wiki/Vanna Venturi House>.

Figura 7: House X (1975). Arq. Peter Eisenman.

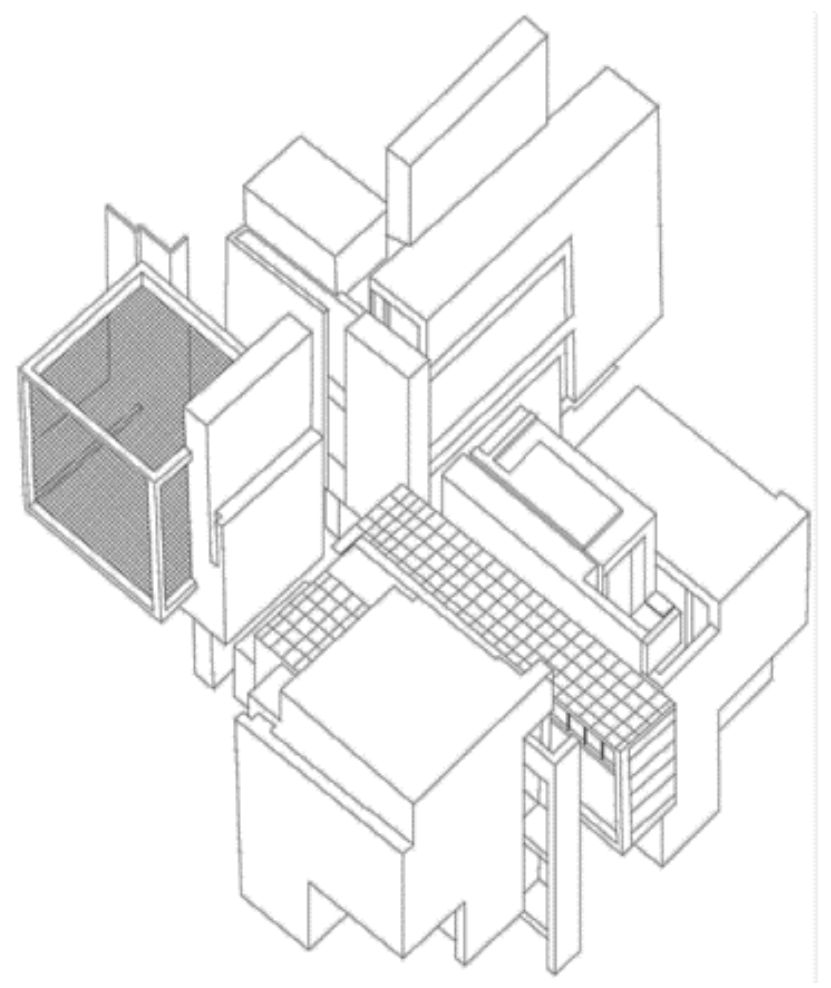

Fonte: Desenho elaborado pelo autor, pertencente ao acervo Rafael Perrone Arquitetos Associados.

Deve-se relembrar que os projetos-tese são apenas um dos formatos pelos quais se pode constituir um trabalho de dissertação ou tese acadêmica. Os formatos variam de acordo com muitas diretrizes e que envolvem o objeto de estudo, métodos de abordagem e objetivos contidos em cada pesquisa. 
Figura 8: Teatro del Mondo (1979). Arq. Aldo Rossi.

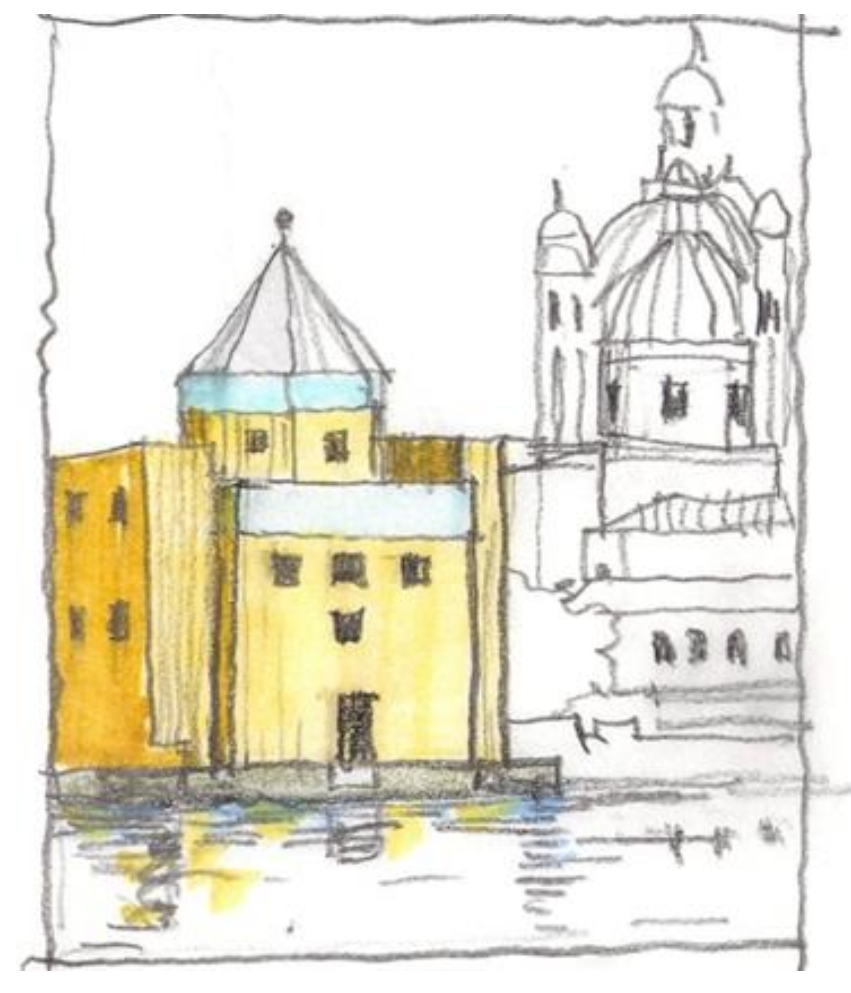

Fonte: Desenho do autor.

Alguns destes formatos de tese podem ser reduzidos aos seguintes tipos definidos na FAUDEU (Faculdade de Arquitetura, Design e Estudos Urbanos da PUC do Chile), conforme nos aponta Del Castillos (2017):

1) Tese convencional: Pesquisa formatada a partir de uma hipótese, que pretende ser uma resposta preliminar às questões formuladas, realiza uma leitura crítica dos fundamentos já conhecidos e do estado da arte em torno do tema para elaborar uma estratégia metodológica adequada. Desenvolve-se um trabalho de pesquisa empírica pertinente verificando a partir de reconhecimentos encontrados a considerações cabíveis para as conclusões relativas à hipótese formulada.

2) Tese conceitual-bibliográfica: Constitui um acervo em relação ao tema abordado, desenvolvendo uma reflexão e debate em torno do tema abordado com base nos conhecimentos já produzidos visando novas interpretações, revisões e novas conclusões.

3) Tese aplicada: trabalho empírico orientado à resolução de um problema como resposta técnica a problemas específicos ou almejando a formulação de diretrizes ou políticas. Avalia o estado da arte conceitual a respeito do tema abordado e desenvolve uma estratégia metodológica aplicada que pretende dar resposta a uma situação problemática. Inclui a proposta e a revisão crítica do procedimento.

4) Tese Projetual: define como centro da pesquisa a elaboração de um projeto que contenha uma formulação teórica e prática que trate de um tema de interesse contendo as definições de caráter propositivo encontradas e suas justificativas no processo decisório envolvido na temática abordada.

Portanto, os projetos que se enquadrem como Tese projetual devem assumir com clareza a explicitação de suas questões, as hipóteses de sua propositura, os métodos utilizados e as formas adotadas no processo decisório pelas quais a definição do projeto se torna uma definição adequada e original das questões abordadas podendo transitar para muitos outros trabalhos de arquitetura.

Para tanto, deve tornar-se claro que as proposituras dos exemplos citados com projetos-tese deverão ser formatadas de modo a se estabelecerem como produtos acadêmicos, quer dizer, um texto escrito por palavras ou um argumento construído por registros desenhados não são, por si só, uma dissertação ou uma tese. Os projetos que se pretendam se tornar dissertações ou teses devem estar formulados e apresentados de modo que possam ser compreendidas suas premissas, seus métodos, seus objetivos, seus objetos de estudo e as conclusões ou argumentos que podem ser extraídos de seus procedimentos. 
Aos projetos-tese caberá estruturar desde a construção do programa até a formulação plástica da obra, refletindo de modo sistemático e criativo sobre as questões e propostas envolvidas no trabalho. Sem esse corpo acadêmico, metodológico e retórico, o projeto poderá até conter uma pesquisa, mas não será uma tese.

No campo da arquitetura e do projeto urbano, a pesquisa finaliza-se pela compreensão e comunicação dos elementos contidos na produção de conhecimentos, em direção à construção do devir. É com o objetivo de constituir esse objeto que reside a pesquisa projetual. Entretanto, o conhecimento não é produzido sem que se compreenda, criticamente, como e porque se constrói o presente e sem que se estabeleça como se deseja o futuro. A ação projetual reside no perfeito entendimento de desejos e necessidades.

Nas demonstrações matemáticas, particularmente nos teoremas da geometria é usual, ao provar a solução, o uso da expressão triunfal CQD: como queríamos demonstrar. Expressão que dificilmente poderíamos utilizar em qualquer tese ou argumento arquitetônico. Nossos saberes, dentro da amplitude gnosiológica da arquitetura, mesmo ficando em débito com as artes, podem entender que a sua pesquisa em área projetual, acompanham, em linhas gerais, os métodos adotados pelas ciências humanas, onde os fatores de indução são os mais utilizados.

As assertivas, neste método, são normalmente construídas por modelos do "tipo de baixo para cima". O processo se desenvolve desde dados empíricos e caminha no sentido de sua interpretação, de um olhar descritivo, para um olhar ativo e explicativo e, na arquitetura, atingindo um "ver" propositivo. Como toda argumentação indutiva, as conclusões e argumentações de um projeto, enquanto pesquisa, são tidas como prováveis dentro do quadro de ocorrências observadas e a ambição de suas conclusões residem nesta delimitação.

Há aqui uma explicação necessária. Toda investigação acadêmica requer um projeto de pesquisa pelo qual se definem ao mínimo: objetivo, problematização, objeto de estudo, método, etapas, hipóteses (em caso de dissertações possibilidades de entendimento) e considerações finais ou conclusões. Portanto, sempre existe um projeto pelo qual a tarefa acadêmica é conduzida.

No caso de um adequado e propositivo Projeto de arquitetura também existem: problema, objetivo, objeto de estudo, uma pesquisa, um método, etapas, hipóteses e resultados. Portanto verifica-se um mesmo rigor que define uma pesquisa com uma problematização, método e determinados fins.

No caso do trabalho acadêmico o projeto de pesquisa envolve percursos para se obter uma tese, dissertação ou artigo. No caso de um Projeto de arquitetura existem percursos similares, os quais, no caso constituem o projeto do Projeto, mas o resultado não são as conclusões ou considerações finais, mas estas são "explicadas" ou definidas pelo Projeto ou plano em si.

\section{Escrita acadêmica e argumentação gráfica}

Há também uma grande gama de formatos pelos quais a arquitetura pode ser estudada, analisada, explicitada para se consolidar como aportes de conhecimentos na área. Os trabalhos e artigos acadêmicos se constituem por textos argumentativos pelos quais as atividades projetuais, as obras, os locais, as situações, as características de uso, memórias, os sistemas construtivos e tecnológicos, contextos físicos, situações espaço- sociais, as contaminações figurativas e mais uma imensa gama de temas podem ser compreendidos sob a área da arquitetura e do urbanismo. Para atender a estes infindáveis objetos de estudo, muitos recursos são requisitados, dentre eles: fundamentos bibliográficos, documentos, fotos, desenhos, manuais, recolha de dados, pesquisas locais, entrevistas artigos referenciais etc. Estes se constituirão como fundamentos e bases para a abordagem metodológica do objeto selecionado, tendo como fim a constituição de argumentos que gerarão uma compreensão referenciada, sistematizada e explicativa do objeto em estudo.

Estes fatores conduzem a verificação de que uma variada gama de abordagens conduz os trabalhos a utilizarem recursos das várias áreas do conhecimento para o desenvolvimento "científico" da pesquisa e a condução à resultados esclarecedores, adequados e satisfatórios.

Em linhas gerais, observa-se que os trabalhos se manifestam por dois grandes conjuntos: os que derivam de abordagens historiográficas e os que se orientam por procedimentos gráficos projetuais. Em uma pesquisa realizada na Universidade Mackenzie em conjunto com a Herdfordshire University, acerca do tema PAPP (Pesquisa em Área de Práticas Projetuais) sobre as vertentes dos trabalhos acadêmicos, relacionados à áreas projetuais de mestrado e doutorado, contidos no acervos até o ano de 2010, da FAUUSP (Faculdade de Arquitetura e Urbanismo da Universidade de São Paulo), LIMA et al. (2011) os tipificaram por meio de dois formatos de apoios investigativos: o indicador o histórico/historiográfico e um indicador gráfico projetual. 
As abordagens gráfico-projetuais que de início estiveram ampliaram suas aplicações quando se fundaram em modos de leitura gerados por vários livros vinculados à interpretação gráfica tendo como foco de leitura diagramas tendo como referência inicial o livro Analysis of Precedent (CLARK e PAUSE, 1983). A continuidade desta abordagem pode ser verificada num contínuo desenvolvimento de interpretações realizadas por vários autores muito bem sintetizados no artigo Teoria e prática em análise gráfica de projetos de arquitetura (TAGLIARI e FLORIO, 2020).

Em um deles deve ser lembrada a afirmação radical de Simon Unwin: "a única forma de entender a arquitetura é através do meio utilizado em sua criação - o desenho" (UNWIN, 2010, p. 3) e contrapô-la à de Till, supracitada, a respeito das obras de arquitetura serem silenciosas. Se as obras de arquitetura são silenciosas, os textos escritos não têm forma, nem luz, nem matéria, nem cor?

A aliança entre os indicadores textuais e os gráficos projetuais parecem ser os recursos metodológicos mais instrutivos para a abordagem da Arquitetura.

Para o tratamento da interpretação e produção de conhecimento da Arquitetura ainda resta uma questão e ela deriva na característica ontológica do Projeto. Numa área projetual não se pode tratar somente de afirmações obtidas de reconhecimento dos fatos e obras existentes, esquecendo-se dos percursos indagativos pertinentes à atividade projetual, além da busca de novas "soluções" derivadas da existência de outros programas e tecnologias, mais ainda da intuição e visão de futuro. Tudo isto aliado a quase sempre peculiaridade de cada novo problema que ocorre para apresentar definir qualquer proposta ou projeto.

Desenhos, como o desenho de Le Corbusier sobre os cinco pontos da arquitetura (fig. 9) não são propriamente confirmações resultantes de um método "científico" de análise de pré-existências e não configuram em "stricto sensu" uma tese sobre as arquiteturas a serem realizadas. Os cinco pontos desenhados e identificados por um texto com algumas legendas são uma produção de conhecimento a qual, como ensaio, tornou-se uma espécie de paradigma da arquitetura moderna.

Figura 9: Os cinco pontos da Arquitetura Moderna por Le Corbusier.

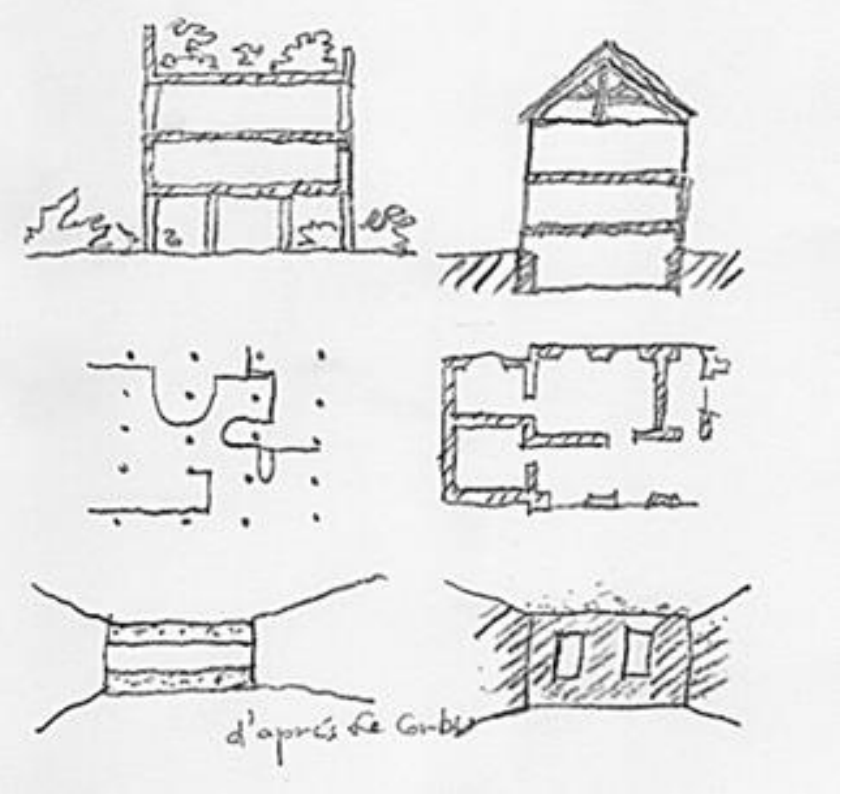

Fonte: Desenho do autor d'après Le Corbusier.

Aqui há de se retomar a validade de que o Projeto resultante da pesquisa possa assumir a característica de um ensaio, por não conter os mesmos atributos "científicos" de uma tida como pesquisa acadêmica. Neste entendimento, pode-se discutir a validade desta forma de exposição que foi tratada por Larrosa em no seu breve texto "O ensaio e a escrita acadêmica" (2003), no qual problematiza as questões políticas acadêmicas da escrita e leitura pelas quais se emanam regras do que se privilegia ou se proíbe:

[...] o ensaio dúvida do método. Não há dúvida de que o método o grande aparelho de controle do discurso, tanto na ciência organizada como na filosofia sistemática. E se há lugar onde o método é questionado, é justamente no ensaio. O ensaio converte o método em problema, por isso é metodologicamente inventivo. O Discurso do método de Descartes é um ensaio. Ocorre, porém, que logo que se converte em metodologia, se fossiliza. Precisamente porque o método, já está dado e já não é um problema. A peculiaridade do ensaio não é sua falta de 
método, mas a de que mantém o método como problema sem nunca o ter como suposto. Uma vez fossilizado, o método é uma figura linear, retilínea. O ensaio, no entanto, seria uma figura de caminho sinuoso, um caminho que se adapta aos acidentes do terreno (LARROSA, 2003, p. 112).

A utilização de um texto "científico" e acadêmico pode e deve ampliar os vários saberes com os quais a Arquitetura produz conhecimentos e se entenda enquanto área de reflexionamento sobre sua teoria e sua práxis.

São sapiências e contém uma argumentação projetual exposta de forma clara, referenciada e concisa, categorizando-se como produção de conhecimento, base para outros projetos e entendimentos.

\section{CONSIDERAÇÕES FINAIS}

A utilização de um texto "científico" e acadêmico pode e deve ampliar as várias compreensões com as quais a Arquitetura possa ser compreendida enquanto área de reflexionamento sobre sua teoria e sua prática.

Le Corbusier fez um ensaio repleto de saberes quando citou e desenhou os cinco pontos da arquitetura, idem fizeram Theo Van Doesbourg com suas Contra composições, Mies com suas casas pátio, Aldo Rossi com seu teatro del Mondo, Hedjuck com suas proposições projetuais, Eisenman com suas Houses, e muitos outros que realizaram propostas baseadas em estudos que apresentam e constituem contribuições para 0 desenvolvimento de novos saberes no campo da arquitetura e da cidade, tanto como textos e argumentos gráficos acadêmicos, como enquanto ensaios baseados em conhecimentos e proposições, contribuições para o desenvolvimento de novos saberes no campo da arquitetura e da cidade.

Estas formas de investigação possibilitaram e possibilitarão uma saudável contribuição entre teoria e a prática reflexiva que caracteriza um projeto de arquitetura ou de urbanismo propiciando um avanço significativo no campo de conhecimento do Projeto.

Sem negar outras e grandes contribuições das demais áreas do conhecimento para a arquitetura, numa época de transdisciplinaridades próprias do campo do Projeto. Campo que envolve as atividades e investigações conceituais-teóricas e práxis reflexivas na tomada de suas decisões e ações de futuridade. Desde modo, pode-se reservar uma peculiaridade ao Projeto, não apartada de outras disciplinas e pertinente ao escopo acadêmico.

Assim, assegurar-se-á uma produção de saberes capazes de conduzir a navegação "por mares nunca dantes navegados" nos quais os instrumentos e conhecimentos resultados das investigações poderão ser guias para novas rotas conduzindo a um futuro cujos resultados deveriam ser mais seguros.

Projetar com máximas precisões, para a imprevisibilidade das vidas.

\section{REFERÊNCIAS}

BIGGS, MICHAEL e BÜCHLER, D. Architectural Practice and Academic Research.Nordic Journal of Architectural Research (20), 2008, p 83-94.

CLARK, R. H. e PAUSE, M. Precedents in Architecture: Analytic Diagrams, formative ideas and Parts. Ed Wiley \& Sons, New Jersey $3^{\circ}$ ed Texto original. Analysis of Precedent. Ed. The student Publication of The School of Design. North Carolina State University, 1979.

DE BOTTON, A. The architecture of Happiness. Nova lorque: Vintage Books,2008. Em português -Arquitetura da Felicidade. Trad. Talita M. Rodrigues. Rio de Janeiro: Rocco, 2007.

DEL CASTILLO PINTOS, A. O papel do projeto na pesquisa acadêmica em arquitetura. Reflexões a partir das práticas. Tese de doutorado FAUUSP: São Paulo 2017

GARNIER, T. Une cité industrielle: étude pour la construction des villes. C. Massin \& Cie, Paris 1917

HOUAISS, A., VILLAR, M. e FRANCO, F. Dicionário Houaiss da língua portuguesa. Rio de Janeiro. Objetiva, 2001

KOOP, A. Quando o moderno não era um estilo e sim uma causa. São Paulo: Nobel / EDUSP,1990

LARROSA, J. O ensaio e a escrita acadêmica. Revista Educação e Realidade, Porto Alegre, vol. 28 n2, julho/dez, 2003 p. 101-117

LIMA, A. G. G. et al. Pesquisa acadêmica em áreas de prática projetual: Arquitetura e Urbanismo (Relatório) - São Paulo, Universidade Presbiteriana $\quad$ Mackenzie. $\quad 2013.61 \quad 61$ p. Disponível em: https://arquiteturadesignmackenzie.files.wordpress.com/2013/04/rtc09032011-final.pdf 
MAHFUZ, E. O projeto de arquitetura e sua inserção na pós-graduação. Arquitextos, São Paulo, ano 02, n. 022.03 , Vitruvius, mar. 2002 Disponível em: http://www.vitruvius.com.br/revistas/read/arquitextos/02.022/800

NESBITT, KATE (ed.). Theorizing A New Agenda for Architecture: An Antology of Architectural Theory 1965-1995. NewYork: Princeton Architectural Press, 1996. p 19.

NOBRE, M. A Teoria Crítica. Rio de Janeiro: Jorge Zahar, 2004.

OLIVA, A. Filosofia da Ciência. Rio de Janeiro: Jorge Zahar, 2003.

PERRONE, R. A. C. A pesquisa em projeto e o projeto como pesquisa, in: Comunicações - Ponencias. XIX CLEFA. São Paulo, Mackenzie, 2001, p 255 a 257.

. A citação como referência e a referência como citação. Revista Pós, São Paulo, V.18 N 30, dez 2011. Disponível em: http://www.revistas.usp.br/posfau/article/view/43753/47375

PLACZEK, A. K. Prólogo del libro. In: WIEBENSON, D.: Architectural Theory and Practice from Alberti to Ledoux. $2^{\mathrm{a}} \mathrm{ed}$. Chicago: University Press, 1983. p. 9-10

ROBBINS, E y CULLINAN, E. Why Architects draw. Cambridge: MIT Press, 1994

SANOVICZ, A. Natureza e Prioridades da Pesquisa em Arquitetura e Urbanismo FAUUSP- Anais. São Paulo: FAUUSP (mimeografado) 1990, p. 111.

SCHON, D. Educando o profissional reflexivo - um novo design para o ensino e a aprendizagem. Porto Alegre: Artemed,2000. Versão original- The Reflective Practitioner: How Professionals Think in Action. New York Ashgate Publishing, 1991.

SERRA, G. G. Pesquisa em arquitetura e Urbanismo - Guia prático para pesquisadores de pós graduação. São Paulo: EDUSP, Mandarim Editora, 2006, p. 16

TAGLIARI, A, FLÓRIO. W. Métodos de análise gráfica: estudo da circulação, percurso e movimento no projeto de arquitetura. Revista Educação Gráfica. V.24, №. 1. Abril de 2020. p. 70 - 89. Unesp, Bauru. Disponível em: http://www.educacaografica.inf.br/artigos/metodos-de-analise-grafica-estudo-da-circulacao-percurso-e-movimento-noprojeto-de-arquitetura-methods-for-graphic-analysis-study-of-circulation-path-and-movement-in-the-architecture-project-2

TILL, J. Is doing architecture doing research? In 4º International Meeting on Architectural and Urbanism Research. Escuela Técnica Superior de Arquitectura de Valencia,2011. Disponível em: https://riunet.upv.es/bitstream/handle/10251/15032/TILL\%20J Is\%20doing\%20architecture\%20doing\%20research.pdf?s equence $=1$

VELOSO, M; ELALI, G. A. Há lugar para o projeto de arquitetura nos estudos de pós-graduação? Arquitextos, São Paulo, ano 02, n. 020.07, Vitruvius, jan. 2002. Disponível em: http://www.vitruvius.com.br/revistas/read/arquitextos/02.020/817

VITRÚVIO, M. Tratado de Arquitetura. Lisboa: IST Press,2006. Tradução de M. Justino Maciel

WIEBENSON, D. Tony Garnier: The cité industrielle. London: Studio Vista, 1969

ZEVI, B. Saber ver a Arquitetura. São Paulo: Martins Fontes, 3 ed.1992

\section{NOTAS}

${ }^{1}$ Fernando Pessoa presta y insere, em seu poema, a ambiguidade da oração" Navigare necesse; vivere non est necesse", frase de Pompeu, general romano, 106-48 A.C., dita aos marinheiros, amedrontados, que recusavam viajar durante a guerra, cf. Plutarco, em Vida de Pompeu.

${ }^{2}$ Na versão em inglês, não foi possível utilizar a ambiguidade dos termos.

3 "Por mares nunca dantes navegados" é um trecho da primeira estrofe - canto 1 do poema épico de Luiz de Camões, no qual enaltecia os navegantes portugueses na época das grandes navegações.

* Este artigo é um desenvolvimento do trabalho apresentado na 4 International Meeting on Architectural and Urbanism Research realizada em Valência, 2011.

NOTA DO EDITOR (*): O conteúdo do artigo e as imagens nele publicadas são de responsabilidade do(s) autor(es). 